\title{
In memoriam : Serge Moscovici (1925-2014) ${ }^{1}$
}

\author{
Réseau Mondial Serge Moscovici (REMOSCO) ${ }^{2}$
}

"Existem momentos privilegiados na vida de um homem, nos quais, ao lançar um olhar retrospectivo sobre a sua vida, ele descobre a que ponto o que para os demais parece uma carreira, para ele foi uma longa série de improvisações e surpresas". Estas foram as primeiras palavras pronunciadas por Serge Moscovici em Berna, no ano de 2003, quando the foi conferido o famoso prêmio Balzan, pela sua obra em psicologia social. Esse prêmio viria coroar um legado profundo deixado à psicologia social como disciplina e sobretudo como ciência.

Nascido em 1925 em Braïla, às margens do Danúbio, numa família de comerciantes de grãos, ele sofreu o impacto do anti-semitismo vigente ao ser expulso do colégio (1938) e viveu o pogrom de Bucarest (1941). Utilizando a rede de "campos para desabrigados" passando pela Hungria, a Áustria e a Itália, ele chega a Paris em 1948. Trabalha no ramo de confecções e de calçados, localiza e encontra os amigos Paul Celan, Isaac Chiva e Isidore Isou. Sua adolescência, com os acontecimentos terríveis que ele viveu durante a guerra e que o marcaram por toda a vida, estão descritos na sua autobiografia Chronique des années égarées (Moscovici, 1997).

\section{Uma trajetória institucional}

Depois de uma chegada épica a Paris, ele obtém, em 1949, a recém-criada "Licenciatura em Psicologia" na Sorbonne (com grau mediano...). Atraído pelas aulas de "psicologia da vida social" do psiquiatra e psicanalista Daniel Lagache, e preocupado com a prorrogação do seu documento de residente como refugiado, ele almeja se inscrever para uma tese de doutorado sob a orientação do famoso professor: "Lagache me recebeu no corredor e ficou surpreso quando declarei meu desejo de defender uma tese sob sua orientação. Por sorte ele estava com tempo para me escutar e eu pude lhe descrever o projeto durante meia hora. Evidentemente, evitei dizer que o estudo se basearia na transformação da psicanálise em matéria do senso comum". (Moscovici, 2003). Lagache, inicialmente cauteloso, sugeriu que ele procurasse Jean Stoetzel, fundador do IFOP (Instituto Francês de Opinião Pública) para obter uma formação em metodologia de pesquisa.

Em Paris, dois locais familiares e duas descobertas o ajudam a encontrar os conceitos tão procurados, as representações coletivas, o senso comum, a comunicação, mas também uma ciência improvável, para tornar sua articulação fecunda, a psicologia social (Moscovici, 2003). Esses locais e as duas descobertas, tão aleatórias quanto importantes, foram os sebos das margens do Sena, onde descobriu Cybernetics de Norbert Wiener e a Biblioteca Nacional da França, onde encontrou l' Essai sur la notion d'expérience, de Robert Lenoble. Lagache o encoraja e o indica para uma bolsa de estudos no CNRS (Centro Nacional da Pesquisa Científica), que ele obtém em 1952. Publica seu primeiro artigo na Revista Francesa de Psicanálise e se inscreve paralelamente, em 1953, na Escola Prática de Altos Estudos para

\footnotetext{
1 Nota: Tradução de Rejane Souza Sales.

2 REMOSCO: Rede internacional de intercâmbio científico sediada na Maison des Sciences de l'Homme de Paris.
} 
acompanhar os seminários de Alexandre Koyré, historiador do pensamento filosófico e científico.

Em 1955, ele se ocupa, no Ministério do Trabalho, dos programas da reconversão industrial, em colaboração com o sociólogo Guy Barbichon, especialista das mudanças sociais, no âmbito do Centro de Estudos e Pesquisas Psicotécnicas (CERP), e dirige, em 1958, a revista do centro, o Bulletin du CERP. Paralelamente ao seu estudo sobre a psicanálise, ele realiza sua segunda tese sobre um problema societal e econômico, ainda atual, a reconversão industrial (Reconversion industrielle et changements sociaux. Un exemple : la chapellerie dans l'Aude, 1961, Albin Michel). Defende sua tese de Doutorado de Estado em Letras, La psychanalyse, son image et son public. Étude sur la représentation sociale de la psychanalyse, em 1961 no anfiteatro Louis Liard da Sorbonne (Jodelet, 2015).

No mesmo ano, obtém o diploma da Escola Prática de Altos Estudos, sob a direção de Alexandre Koyré, com uma tese sobre a mecânica de Galileu (L'expérience du mouvement. Jean-Baptiste Baliani, disciple et critique de Galilée, 1967). Baseada nos manuscritos conservados na Biblioteca Ambrosiana de Milão, essa tese envolve as origens de suas idéias sobre a ciência, o conhecimento e a natureza. Baliani, patrício genovês, a quem devemos a primeira formulação do princípio da inércia, já postulava desde 1582, ao contrário de Galileu, que a terra girando em torno da lua, sofria dessa última uma influência mecânica sobre as marés. Moscovici se inspira na sua correspondência para teorizar sobre a incerteza criadora da ciência, ou seja, o fato de que o homem criou a natureza através da ciência. Esse trabalho lhe abre as portas do Instituto para Estudos Avançados de Princeton (recomendado por Koyré que era membro desde 1955), como Fellow em 1962-63. Nos Estados Unidos, em Yale e em Harvard, ele profere suas primeiras conferências em inglês e encontra-se com Thomas Kuhn.

Nomeado Mestre de pesquisas no CNRS em 1962, foi eleito Diretor de estudos na Escola Prática de Altos Estudos em 1964. No mesmo ano, torna-se membro do Comitê Transnacional de Psicologia Social do Conselho de Pesquisa em Ciências Sociais, cuja história fascinante foi escrita recentemente (Moscovici \& Markova, 2006), ao lado, entre outros, de Leon Festinger, John Lanzetta, Ragnar Rommetveit e Stanley Schachter e, logo depois, Henri Tajfel, Harold Kelley, Morton Deutsch... Foi um dos fundadores da EASP, seu primeiro Presidente em 1965 e editor associado do Jornal Europeu de Psicologia Social (1969-1974).

Em Paris, no âmbito do "Grupo de Estudos de Psicologia Social ", seu primeiro laboratório criado em 1965 na 6ạ. Seção da Escola Prática de Altos Estudos, ele reúne um grupo pioneiro de pesquisadores cujos trabalhos se inscreviam nas suas linhas de interesse científico (dentre os quais: Claude Faucheux, Claudine Herzlich, Jean-Claude Abric, Denise Jodelet e Willem Doise). É quando inicia um amplo programa de pesquisas experimentais consagrado essencialmente à influência e à comunicação social.

Seguindo um caminho intelectual paralelo entre história das ciências e psicologia social, ele realiza, entre 1968-1969, uma nova temporada americana no Center for Advanced Studies in the Behaviourial Sciences (Stanford) e publica, em 1968, outra obra monumental I'Essai sur l'histoire humaine de la nature. A França está em plena ebulição social, ideológica, política e geracional, e essa reflexão sobre a natureza, a primeira de uma forma de trilogia (as duas seguintes são La société contre nature, 1972 e Hommes domestiques et hommes sauvages, 1974) inaugura sem dúvida o "período verde" de Moscovici (o período mais desconhecido dos psicólogos sociais). Suas idéias antropológicas sobre a natureza, o feminismo e a ecologia política traçam um novo horizonte para as gerações de jovens 
estudantes e militantes: a natureza é uma relação, não o ambiente; nenhuma parte da humanidade, por mais primitiva ou avançada que seja, está mais próxima ou mais afastada de um estado de natureza; a análise da proibição do incesto como regra social permite captar as relações de dominação e de regulação entre grupos. Uma teoria da sociedade está em andamento.

Essa aventura intelectual o leva a encontrar Robert Jaulin (teórico do etnocídio), que dirige a Unidade de Ensino e de Pesquisa de etnologia, de antropologia e de ciências da religião da Universidade Paris 7 (Jussieu). Com a participação, entre outros, de Michel de Certeau, Jean Monod e Jean-Toussaint Dessanti, montam seminários " selvagens ", " aulaspiratas de etnologia anticolonial», obtendo um franco sucesso junto aos estudantes, militantes e intelectuais ecologistas. Moscovici se envolve, milita, escreve (as obras coletivas, Pourquoi la mathématique, 1974 ; Au-delà de la crise, 1976 ; Pourquoi les écologistes font-ils de la politique ?, 1978). Com um dos grandes gênios matemáticos do século passado, Alexander Grothendieck, falecido dois dias antes dele, juntamente com Jaulin e o documentarista Yves Billon, eles percorrem o sul da França com uma exposição de fotografias intitulada "Occitanie, Amazonie, même combat ", com o objetivo de denunciar o etnocídio das pequenas populações locais e tradicionais, onde quer que ocorressem.

Essa atividade frenética alimenta sua produção psicossocial: ele edita um livro de textos fundamentais em inglês (The psychosociology of language, 1972), dois volumes da Introduction à la psychologie sociale (1972-73), publica em inglês sua teoria da inovação das minorias (Social influence and social change, 1976) e edita uma versão revista, com uma centena de páginas a menos, de sua obra de 1961. Tem uma intensa atividade internacional como professor convidado da New School for Social Research (New York, 1970-72), do Institut Jean-Jacques Rousseau de I'Université de Genève (1972-73), da 'Université de Louvain (1976), ocupa a cadeira Franqui na Universidade de Louvain-la-Neuve (1976), é Fellow da Van Leer Jerusalem Institute (1977) e do Churchill College da Universidade de Cambridge (1980). Durante quinze anos (1980-1995), ele será Professor Visitante da New School for Social Research (New York). Esse aumento progressivo do reconhecimento internacional da sua obra vem acompanhado da criação de várias comunidades de pesquisadores de países diferentes que se formam, discutem, fazem avançar as idéias princeps, estabelecem práticas comunitárias acadêmicas (p.ex. conferências bianuais internacionais, conferências brasileiras, formações doutorais europeias, centros Moscovici). A chegada dos anos 2000, marca a consagração internacional de sua obra e, segundo suas próprias palavras, da obra de um coletivo (Moscovici, 2004).

O reconhecimento mundial dessa obra é muito significativo. Entre 1980 e 2012, foramIhe concedidos quinze títulos honoris causa, majoritariamente na Europa (Genebra, Glasgow, Sussex, Sevilha, Bruxelles, Bolonha, Londres, Roma, Pécs, Lisboa, Jönköping, lasi, Évora), mas também na América Latina (México e Brasília). Recebeu seis prêmios internacionais (1980, Prix In Media Res, Fondation Burda; 1989, Prix Européen des Sciences Sociales et de Sociologie ; 2000, Prix Ecologia ; 2003, Prix Balzan ; 2007, Prix W. Wundt \& W. James ; 2010, Premio Nonino), homenageando todas as facetas do seu pensamento.

\section{Principais contribuições trazidas pelo seu trabalho}

Com relação ao estudo das representações sociais, um dentre nós (Kalampalikis, 2013, pp. 8-9) na introdução da última obra em francês de Moscovici (Le scandale de la pensée 
sociale, 2013) destaca o que considera relevante: a conversão de uma forma de conhecimento científico em um sistema composite de opiniões e de interpretações do real; a dinâmica da constituição do conhecimento e do pensamento sociais na comunicação, e a ação de grupos posicionados histórica e culturalmente. O objetivo, tão holístico quanto ambicioso, declarado pelo autor em 1961 é duplo. Primeiramente, o de dotar essa nova disciplina, a psicologia social, de uma "matéria", de um horizonte epistemológico próprio, estudando os estados representacionais como formas de conhecimento. Posteriormente, enraizá-la no âmbito das ciências do social tanto por uma "unidade de preocupações" no presente, quanto pelas correntes de idéias comuns que a moldaram (Jodelet, 2011). Para atingir esse objetivo ambicioso e radical, dado o estado proteiforme da psicologia social na Europa e o ostracismo relativo da contribuição durkheimiana nas ciências sociais da época, era preciso inovar, tanto no âmbito interno quanto no externo do campo disciplinar principal da teoria. No âmbito da psicologia, foi preciso romper com as correntes behavioristas e individualistas norte-americanas dominantes, que descartavam a dimensão reflexiva e simbólica do comportamento humano em sociedade (Greenwood, 2004). No âmbito das ciências sociais, a ruptura consistia em introduzir a legitimidade científica do estudo do senso comum dentro de uma "sociedade pensante" face às críticas dos modelos ideológicos e epistemológicos dominantes, a fim de reivindicar ao mesmo tempo a proximidade epistemológica e o lugar específico da disciplina (Jodelet, 2009).

Durante a elaboração desses primeiros trabalhos, Moscovici desenvolve duas hipóteses que viriam ocupar quase todo o restante de sua carreira científica. Ele dirige a história da ciência para o estudo da relação entre dois domínios de conhecimento incontornáveis: a ciência e o senso comum. Para ele, a epistemologia apenas aflora a análise das relações entre esses dois tipos de conhecimento. Ocasionalmente ele gostava de citar Einstein para afirmar que a ciência sem o senso comum cairia no solipsismo. Passa então a se interessar pela interação não hierárquica entre o saber científico e o conhecimento social, isto é, o saber dizer e fazer próprios do senso comum: como se transformam mutuamente, como o conhecimento de um transfere-se ao outro e vice-versa.

A obra Princeps (1961) põe em evidência dois processos sociocognitivos, a objetivação e a ancoragem, que funcionam como bielas transformando o movimento linear em movimento circular e através dos quais o nível de abstração de uma teoria científica se concretiza por poder fazer parte da cultura do senso comum e das práticas cotidianas. Dentre as várias hipóteses ali abordadas, Moscovici destaca que cada coletivo fabrica suas próprias bielas, que lhe servem para ancorar esse conhecimento nomotético em algo de idiográfico. Essas ferramentas são sistemas de comunicação que levam sempre uma parte do destinatário e do emissor. Assim, um dos aspectos mais originais de sua obra é a análise dos sistemas de comunicação, sobre a maneira pela qual o emissor, antes mesmo de construir sua mensagem ou selecionar as informações que vai transmitir, leva sempre em conta a relação social e portanto a influência que ele visa exercer junto ao receptor. Essa análise dos sistemas de comunicação foi principalmente aplicada na comunicação midiática inspirando outros trabalhos (Doise \& Palmonari, 1986). Dentre esses sistemas ou gêneros de comunicação ele destacou a difusão (quando a comunicação visa atravessar as fronteiras dos pertencimentos a categorias), a propagação (correspondendo à comunicação dentro de um grupo social dado) e a propaganda (comunicação visando acentuar as diferenças entre grupos ou categorias sociais) 
Essa proposta se baseia numa crítica do modelo clássico da comunicação de Lasswell, que na época guiava a massa dos estudos sobre a mudança de atitude. Em um dos seus primeiros artigos (Attitudes and Opinions, publicado no Annual Review of Psychology en 1963), ele critica essa tradição de pesquisa. Esse modelo exclui a interação bidirecional que é essencial na comunicação e na influência. Não há mensagem, retórica ou linguagem fora de contexto. Nenhuma elaboração de mensagem é feita num vazio social. Emissor e receptor se influenciam mutuamente na construção da mensagem. Não existe escrita que não leve em conta o público ao qual se dirige ou que se imagina que irá lê-la.

Essas hipóteses serão desenvolvidas nos seus trabalhos sobre a linguagem. Num capítulo publicado em Advances in Experimental Social Psychology (1967), bem como no livro The Psychology of Language (1972) ele nota que não existe um campo que possa ser designado como psicologia social da linguagem, e tenta formular o que deveria ou poderia ser incluído nesse campo. Moscovici começa por questionar a distinção hegemônica de Saussure entre a linguagem - sistema estável de relações entre unidades léxicas - e a palavra - conjunto de usos desse sistema pelos membros de uma comunidade falante. Para ele, a comunicação é um processo de produção linguística. A organização da palavra é o primeiro ponto examinado, pois é quando se combinam elementos léxicos e não léxicos. Baseando-se no conhecimento existente sobre as relações entre emissores e receptores, sua motivação e seu distanciamento com relação ao objeto considerado, torna-se possível predizer as características da mensagem - formas gramaticais, redundâncias, grau de formalismo - correspondendo à situação da correspondência. Os sistemas de comunicação estão ligados aos sistemas sintáticos e léxicos. Os locutores reais, os criadores reais das formas de linguagem são os grupos: classes, nações, profissões, grupos culturais, culturas rurais e urbanas. As diferenças existentes entre esses grupos ultrapassam amplamente, do ponto de vista qualitativo e quantitativo, as diferenças que aparecem no nível individual. Ele observa que a criatividade linguística é provocada e estruturada pelas trocas coletivas. Ainda que alguns frequentemente considerem que a linguagem, como comunicação, mantém a ligação social, parece-lhe que seria também correto estabelecer uma ordem inversa. As forças coesivas, os conflitos, negociações, celebrações e ritos que caracterizam uma determinada sociedade são fatores que criam as regras linguísticas e metalinguísticas, provocando sua combinação e sua difusão.

Moscovici nunca compreendeu por que alguns psicólogos sociais procuravam no indivíduo e no seu cérebro o que se encontrava na interação social. É nessa interação que se propaga, se estende e se cria o conhecimento social, pois, definitivamente, não há transmissão sem transformação. Esse processo de comunicação, específico da espécie humana, cuja informação não é tratada, mas interpretada, será para ele um princípio que nenhuma teoria psicossocial deveria ignorar. Em várias ocasiões ele foi muito crítico com relação à metáfora cibernética do homem como máquina de tratar a informação, que induzia a psicologia social a supor o social, reduzindo o conhecimento social à "cognição social".

Seu primeiro contato com a psicologia social dos Estados Unidos, a única a ser institucionalizada na época, foi midiatizada pelo grupo de psicólogos de tradição lewiniana. Seguindo essa tradição, ele situa a mudança e a inovação na interação entre indivíduos e grupos sociais. Ele vê na discussão ativa, na expressão das divergências, e principalmente no conflito (no sentido de Simmel), os mecanismos da mudança. Assim, juntamente com Claude Faucheux ele explorou a hipótese sobre a maneira pela qual a comunicação se estrutura no 
interior de um grupo (centralizada $x$ livre) provocando um efeito sobre o desempenho (os grupos com uma estrutura centralizada resolviam melhor as tarefas lógicas muito estruturadas, enquanto que os grupos com uma comunicação livre tinham melhores resultados nas tarefas de criatividade).

Em várias ocasiões ele ressalta a sorte de ter participado das primeiras reuniões organizadas por Lanzetta na Europa, onde ele teve a oportunidade de conhecer Festinger, Schachter, Deutsch, Pepitone, entre outras figuras da psicologia americana. Ele estabeleceu uma sólida colaboração e uma amizade profunda com Festinger, que sem dúvida lhe inspirou vários princípios com relação à disciplina da psicologia social. Por um lado, a importância do método experimental. Importância que não impediu Moscovici, em nenhum momento, de praticar a mais ampla diversidade, chegando até a pregar o "politeísmo metodológico ». De certa maneira pode-se dizer que ele sempre manteve alguma coisa de wundtiano, pensando que existem fenômenos nas representações sociais e no saber tradicional, dificilmente abordáveis experimentalmente, quando o fundamento epistemológico da teoria que os subentende é de natureza explicativa. Além disso, ele tinha uma concepção da experimentação enquanto experiência inventiva, onde se descobre algo de novo. De certa maneira, ele nunca levou muito a sério o mantra da experimentação como estratégia de verificação de uma teoria de valor previsível. Não faltaram colóquios onde se podia ouví-lo dizer, mais ou menos brincando, "se a experiência contraria a teoria, pior para a experiência ». Ele ouvia e lia as experiências minuciosamente, prestando uma atenção especial em captar se a experiência tinha simplesmente variado um parâmetro ou se ela abordava realmente uma variável. Era muito crítico com relação à tendência que se limita a repetir experiências apenas para fazer variar um parâmetro a mais, deixando de lado o problema ou o verdadeiro fenômeno estudado.

Essa entrada na psicologia social através de figuras como Festinger o levou a seguir ao pé da letra o conselho que lhe repetia o mesmo Festinger nas várias reuniões compartilhadas no âmbito do Comitê Transnacional, segundo o qual os psicólogos sociais da Europa não deveriam se dedicar a replicar os estudos feitos pelos psicólogos sociais nos Estados Unidos... na tentativa de encontrar diferenças culturais. Ele citava como exemplo o artigo o seu colega e amigo próximo Claude Faucheux (Cross-cultural research in experimental social psychology, publicado em 1968 no EJSP). Manteve-se um defensor ardente da importância do estudo de nossa cultura em contextos políticos e históricos precisos.

Sua dedicação à psicologia social coincidiu também com a "crise" da psicologia social. Apesar de que essa crise se concentrava principalmente nas questões metodológicas, a questão para ele era mais epistemológica. Tratava-se de definir a " matéria » dessa ciência. Essa " matéria » é para ele o senso comum, da mesma maneira que a linguagem é a matéria dos linguistas, o mito a dos antropólogos, os sonhos a dos psicanalistas, a vida celular a dos biólogos ou o mercado a dos economistas. Além disso, ele teorizou a visão dessa disciplina, o olhar psicossocial, propondo uma leitura ternária dos fatos e das relações, a fim de substituir a relação de dois termos do sujeito e do objeto por uma interação, isto é, uma relação de três termos (sujeito individual (ego) - sujeito social (alter) - objeto).

Um tema transversal na sua obra, e não apenas na de psicologia social, é o estudo da inovação. Como era seu hábito, ele primeiro observava um fenômeno geral e depois procurava conceituá-lo e analisá-lo. Ele simplesmente observou que as sociedades mudavam, fosse qual fosse o ritmo. E se perguntou então se isso se devia a processos de 
inovação, na origem do conhecimento social. Sobre essa questão ele propôs duas teorias: a da polarização coletiva, e a da influência das minorias, que foram mais divulgadas entre os psicólogos sociais mainstream, se nos permitem a expressão.

A partir de 1969, através de vários artigos, principalmente com Marisa Zavalloni, ele publica a sua teoria da polarização coletiva. Até então um bom número de psicólogos sociais reduzia a tomada de decisões em grupo a uma forma de agregação de decisões individuais, onde a situação do grupo diluía a responsabilidade individual. Mas Moscovici partia de uma questão muito mais ampla: como polarizar a atenção sobre um tema ou outro na sociedade, e em seguida como vão se polarizar os sentimentos sobre esse tema. Se é evidente que os líderes de opinião ou os mass-midia determinam uma boa parte dessa agenda temática para a sociedade, a questão original que o interessava tinha a ver com a maneira como se rompe a simetria na qual se encontram, em um determinado momento, as interações no interior de um coletivo, e o que acontece em seguida. Dentro da tradição lewiniana e festingeriana, ao grupo normalizador que faz pressão sobre a referência e a conformidade, opõe-se o grupo que faz pressão sobre a inferência, aquele no interior do qual surgem dissidentes ou divergências do conteúdo, que terminam por quebrar a simetria, tendo como efeito dirigir a interação social para a mudança e a inovação. Ele demonstrou que num grupo de discussão podem surgir abordagens que não figuravam inicialmente em nenhum dos indivíduos pertencentes ao grupo. Ele tentou generalizar os fenômenos de poder e de conformidade observados nas experiências e publicações realizadas com um físico, Serge Galam.

Ele compreendeu rapidamente que quando um coletivo é levado a polarizar sua atenção em um determinado tema, e a instaurar um debate ou uma viva discussão, as opiniões e os sentimentos vão se polarizar sobre o ponto para o qual eles tendiam inicialmente. Na obra escrita com Willem Doise (Dissensions et consensus. Une théorie générale des décisions collectives, 1992) eles mostram como ir ao encontro do pensamento de grupo, como transformar um grupo normalizador e conformista em um grupo inovador, criador e eficaz. As organizações obteriam grandes benefícios se levassem em conta essas contribuições.

Ao mesmo tempo em que se dedica a esses trabalhos, Moscovici se interessa à influência social e à mudança social. Em Social influence and social change, ele examina em profundidade as teorias propostas em teoria social para comprovar a influência social. Chega então a duas conclusões máximas. Por um lado, essas teorias confundem influência social e poder. Elas reduzem a influência ao fato de dispor de um poder (normativo, informacional, referencial), o que resulta no aumento da conformidade. Por outro lado, nenhuma delas é capaz de comprovar a inovação social. Sua experiência no movimento ecologista ensinou-o que as minorias sociais são atores sociais essenciais e inovadores. Então ele levanta duas questões fundamentais: uma minoria social, sem nenhum poder, pode influenciar? Em caso afirmativo, de que maneira ? Suas primeiras experiências nesse campo visam descobrir que a influência minoritária existe. Isso pode parecer simples, mas é preciso saber que para Moscovici a experimentação visa a descoberta de fenômenos, muito além do simples contraste de hipóteses. Nos bastidores, ele lamentava o pouco risco assumido ao se fazer experiências com a intenção de descobrir novidades.

Finalmente ele propõe seu modelo genético interacionista da influência social. Na origem da inovação, ele coloca o estilo de comportamento da minoria, principalmente a consistência, isto é, a simples repetição sem contradição de uma alternativa. Seria a única maneira pela qual uma minoria social poderia gerar conflitos sociais e forçar a maioria a 
pensar o que a minoria quer dizer e, em um determinado nível, a repensar suas próprias propostas anteriores. Ele vê também que a natureza da influência exercida por uma maioria é diferente daquela exercida por uma minoria, o que o levará a escrever a teoria da conversão, publicada nos anos 1980, entre outras, nos Advances in Exper. Soc. Psychol. Ao longo de toda a sua vida, ele viu nas minorias sociais ativas o meio de liberar uma coletividade, uma sociedade, dos seus próprios hábitos normativos.

Nós nos limitamos, e certamente nos limitamos demais, a prestar essa curta homenagem aos principais legados que Moscovici nos deixou para a psicologia social. Não podemos aqui esboçar um quadro mais completo de uma carreira intelectual e científica tão longa, ativa, criativa e original, ancorada plenamente nas ciências humanas e sociais. Dentre as suas contribuições incontestáveis, figuram suas releituras dos grandes clássicos da psicologia das massas, como, por exemplo, Le Bon, Tarde, Freud (L'âge des foules, 1981). Ele também voltou às fontes dos fundadores das ciências sociais como Weber, Durkheim, Simmel (La machine à faire des dieux, 1988), e singularmente da psicologia coletiva, a fim de defender o inseparável do social e do psíquico nas nossas análises.

Suas duas « invenções » institucionais, o Laboratório de PsicologiaSocial da Escola de Altos Estudos em Ciências Sociais e o Laboratório Europeu de Psicologia Social da Fundação Casa das Ciências do Homem, marcaram várias gerações de pesquisadores do mundo inteiro. O primeiro reuniu e formou durante quase quatro décadas, pesquisadores em uma psicologia social específica, de orientação decisivamente societal, atualmente reconhecida e claramente identificada no âmbito de uma ampla comunidade internacional. Mais de 90 teses foram defendidas nesses laboratórios de 1966 a 2007 (das quais 59 sob a sua direção). Uma grande parte de pesquisadores assim formados integrou instituições acadêmicas na França, na Europa e no mundo.

O segundo, o Laboratório Europeu de Psicologia Social (LEPS), foi criado por Moscovici em 1976 na Fundação Casa das Ciências do Homem (FMSH) em Paris. Ele viria reforçar as correntes de pesquisas européias originais, mas desconexas, completando assim a ação da Associação Européia. Vários grupos de pesquisa permitiram a emergência de temáticas inovadoras e interdisciplinares e reforçaram o trabalho colaborativo entre pesquisadores, 0 que resultou em várias publicações coletivas. Seu funcionamento original em rede, bem antes que esse modelo de trabalho interativo se tornasse corrente, fez do LEPS um raro exemplo de inovação institucional (Kalampalikis, 2003).

Após trinta anos de atividade, Serge Moscovici acompanhou a evolução desse trabalho, suscitando a criação de uma nova rede, a "Rede Mundial Serge Moscovici » (REMOSCO) na FMSH, que tem como vocação ampliar e perenizar a inventividade da sua obra através da ampla comunidade internacional de pesquisadores que se baseiam nos seus trabalhos.

A história dos homens é indissociável daquela das idéias. Serge Moscovici atravessou a história do século XX e marcou profundamente as ciências sociais. Seu desaparecimento nos impõe o reconhecimento de toda a dimensão de sua obra polimorfa e, em especial, dentro de uma disciplina, de uma ciência, que ele desejou aberta, curiosa, inventiva, sensível, e alinhada com as questões societais do seu tempo. Uma psicologia social que " estuda como e por que nós procuramos compreender o mundo hic et nunc, e a agir sobre ele "; o que significa, uma antropologia de nossa cultura (Moscovici, 2012). 


\section{Referências bibliográficas}

Buschini, F., \& Kalampalikis, N. (Eds.) (2001). Penser la vie, le social, la nature. Mélanges en l'honneur de Serge Moscovici. Paris: Éditions de la Maison des sciences de l’homme.

Doise, W., \& Palmonari, A. (Eds). (1986). L'étude des représentations sociales. Neuchâtel, Delachaux e Niestlé.

Greenwood, J. D. (2004). The disappearance of the social in American social psychology. New York: Cambridge University Press.

Jodelet, D. (2009). Rappresentazioni e scienze sociali: incontri e rapporti reciproci. In A. Palmonari \& F. Emiliani (Eds.). Paradigmi delle rappresentazioni sociali. Roma: II Mulino.

Jodelet, D. (2011). Returning to past features of Serge Moscovici's theory to feed the future. Papers on Social Representations, 20, 39.1-39.11.

Jodelet, D. (2015). Représentations sociales et mondes de vie [Social representations and life-worlds]. Paris: Editions des Archives contemporaines (forthcoming).

Kalampalikis, N. (2003). Un laboratoire sans murs : le LEPS. Journal des Psychologues, $\mathrm{n}^{\circ}$ hors série sur « Serge Moscovici : le père de la théorie des représentations sociales. 16 contributions pour mieux comprendre ", 50-54.

Kalampalikis, N. (2013). Retour au milieu vital. In S. Moscovici. Le scandale de la pensée sociale (pp. 7-15). Paris: Éditions de l'Ehess.

Moscovici, S. (1997). Chronique des années égarées. Paris: Les Éditions Stock.

Moscovici, S. (2003). Le premier article, Journal des Psychologues, $n^{\circ}$ hors série sur « Serge Moscovici : le père de la théorie des représentations sociales. Seize contributions pour mieux comprendre », 10-13.

Moscovici, S. (2004). Questions de Psychologie Sociale. In Premi Balzan 2003. Laudationes, discorsi, saggi (pp. 137-151). Milão: Libri Scheiwiller.

Moscovici, S. (2012). Raison et cultures [Reason and cultures]. Paris: Éditions de l’Ehess.

Moscovici, S. (2013). Le scandale de la pensée sociale [The scandal of social thought]. Paris: Editions de l'Ehess.

Moscovici, S., \& Markova, I. (2006). The Making of Modern Social Psychology. Cambridge : Polity Press. 